\title{
Review of PhD Theses on the Role of Personality in SLA
}

\author{
Shahila Zafar (Corresponding author) \\ Assistant Professor, School of Social Sciences and Languages \\ VIT University, Vellore-632014, TN, India \\ E-mail: shahela.zafar@gmail.com \\ K. Meenakshi \\ Associate Professor, School of Social Sciences and Languages \\ VIT University, Vellore-632014, TN, India \\ E-mail:k.meenakshi@vit.ac.in
}

Received: May 13, 2011

doi:10.5539/ells.v2n1p94
Accepted: September 19, 2011

Published: March 1, 2012

\begin{abstract}
Individual variability of second language learners is considered one of the most important factors in the second language acquisition. This paper discusses the $\mathrm{PhD}$ level research conducted in the area in various universities. In all, the different personality variables like empathy, self- esteem, anxiety and extroversion/ introversion are defined first. This is followed by a discussion on five theses that deal with the different aspects of relationships between a second language learner's personality and his/ her proficiency in the second language. A summary of the work done by the researcher, the methodologies used, conclusions reached, is given.
\end{abstract}

Keywords: Second language acquisition, Personality, Second language research, Research, Individual variability

\section{Introduction}

Many factors influence the process of the second language (SL) learning. Yet, one of the most important elements for second language acquisition (SLA) research is the great individual variability SL learners obtain in their respective second language (L2) (Gass, 1988). It has been frequently observed that different learners attain highly different levels of L2 proficiency even though the circumstances in which these learners acquire a target language are almost identical. This interindividual variation can be accounted for by learner-internal factors. Johnson (2001) divided the variables that contribute to differences between individual language learning into three categories: cognitive, affective, and personality variables. Skehan (1989) explained that cognitive factors include various forms of mental information processing; affective factors involve motivation and anxiety and personality variables are mostly associated with a set of personality traits.

\section{Personality}

Personality is considered a very important category of individual differences since the individual is often judged depending on her/his personality. According to Wright \& Taylor (1970), "Personality refers to those relatively stable and enduring aspects of the individual which distinguish him from other people, and at the same time, form the basis of our predictions concerning his future behavior". Another definition that captures much of what psychologists mean by personality is Child's (1968) description of personality characteristics as more or less stable, internal factors that make one person's behavior consistent from one time to another, and also from one situation to another and different from the behavior and reaction other people would manifest in comparable situations. Therefore, it is expected that any given individual will behave in a reasonably consistent manner on different occasions.

\subsection{Attributes of Personality}

Personality as a construct, therefore, has a number of attributes. According to Peterson (1992), personality has the following features:

i. It is an integrated part of an individual - something a person is, does or has. People bring their personalities to situations and take them away with them when they leave. 
ii. It is psychological - refers to the individual (actions, thoughts, feelings) and not to material things such as possessions or status.

iii. It is made up of smaller units called characteristics - the combination of these individual characteristics creates a unique psychological signature.

iv. It can be functional or dysfunctional - that is, our characteristics can help us succeed and prosper in some situations but they can also disadvantage us or make us vulnerable in others.

\subsection{Personality Variables in SLA}

Personality can have a profound influence on second language achievement. We need to study human personality to answer the perplexing problems in language learning. Personality has been described as a set of features that characterize an individual. It has been stated that this concept is difficult to define and measure because of its complicated nature. Studies that investigate personality traits are based on the belief that learners bring to the classroom not only their cognitive abilities but also affective states which influence the way they acquire a language. Some of them have been found as benefits while the others as obstacles in learning a second language. Brown (2000) lists self-esteem, inhibition, risk-taking, anxiety, empathy, and extroversion as personality factors. A discussion of these variables includes brief literature reviews of work done on them in the field of SLA. The following sections explain each of these personality variables:

\subsubsection{Self-esteem}

People need some degree of self-esteem and self-confidence in order to succeed in any activity. Coopersmith provided the following definition of self-esteem: "By self-esteem, we refer to the evaluation which the individual makes and customarily maintains with regard to himself; it expresses an attitude of approval or disapproval, and indicates the extent to which an individual believes himself to be capable, significant, successful and worthy" (as cited in Brown, 2000, p. 142)) People develop their sense of self-esteem as a result of the information they receive about themselves from others. Brown (2000) mentioned three levels of self-esteem: global, situational and task self-esteem. He claims that situational self-esteem "might refer to SLA in general, and task self-esteem might appropriately refer to one's self-evaluation of a particular aspect of the process: speaking, writing, a particular class in a second language, or even a special kind of classroom exercise". Williams and Burden (1997) present social comparison theory that claims that classroom interactions have a great influence on how learners perceive their abilities. Their sense of achievement is strongly affected by the information they get from the teacher and their peers in the classroom. Teachers should realize that they influence not only students' academic performance but also their emotional states. They should create such atmosphere in the classroom that will help to build students' confidence and lead them to success. The results of the research suggest that self-esteem is an important variable in SLA. Many studies show a positive relationship between high self-esteem and academic achievement (Brodkey, \& Shore, 1976); Gardner and Lambert, 1972).

\subsubsection{Inhibition and Risk-taking}

It has been suggested that inhibition influences language learning in a negative way because it discourages the risk taking, which is an essential element in this process. It is necessary to make mistakes if a person wants to learn a foreign language. People make hypotheses about the language and then test them out by trial and many errors. Brown (2000) states that if learners do not want to speak until they are absolutely certain that they are correct they will never acquire communicative skills. This is mainly a problem of adults who are more self-conscious than children are. A child adopts a new language and accent more rapidly than an older person who is less open to the influences and changes. The next thing that language learners have to face is the loss of status. They must accept the fact of being depended on others and sometimes be prepared to reveal their weaknesses or look foolish. According to Stern (1983), "an individual who is detached, self-critical, and has a sense of humor can cope with this demand of language learning better than a rigid or status-conscious individual who lacks self-awareness or humor". It has been also suggested that tolerance of ambiguity is an advantageous feature as learning a second language is closely connected with baffling and confusing situations. Stern (1983) observes that "the learner who is capable of accepting with tolerance and patience the frustrations of ambiguity that second language learning inevitably involves is emotionally in a better position to cope with them in a problem-solving frame of mind than a student who feels frustrated or angry in ambiguous situations".

\subsubsection{Anxiety}

Anxiety is another important aspect of personality that affects learning a foreign language. Brown (2000) describes anxiety as a state of mind connected with "feelings of uneasiness, frustration, self-doubt and worry". MacIntyre and Gardner (1991) distinguish anxiety into two types: (1) trait anxiety- a general predisposition to be anxious and (2) 
state anxiety- experienced in a particular situation. They also identify three components of foreign language anxiety namely: communication apprehension, fear of negative social evaluation and test anxiety. Their studies show that "foreign language anxiety can be distinguished from other types of anxiety and that it can have a negative effect on the language learning process". Here, it is also important to differentiate between debilitative and facilitative anxiety. Although anxiety is regarded as a negative factor which must be avoided, the concept of facilitative anxiety, "a little nervous tension in the process", is a positive factor. It must be remembered that "both too much and too little anxiety may hinder the process of successful second language learning" (Brown, 2000).

There has been some research that investigated the reasons of the state anxiety in the classroom. Bailey in 1983 found that competitiveness among students, their relationship with a teacher and tests could increase anxiety. Skehan states that anxiety can be a result of low achievement. Poor and average students are prompt to encounter failure because of debilitative anxiety more often than high-ability students are. It was also suggested that a different kind of anxiety appears depending on the level of students. The more proficient learners are the more facilitating anxiety they experience (Scovel, 1978).

\subsubsection{Empathy}

The other aspect of personality that has been studied is empathy - "the willingness and capacity to identify with others" (Stern, 1983). Researchers still have not confirmed a direct relationship between the quality of empathy, or the ability "to put oneself in someone else's shoes" (Raymond, 1982) and achievement in learning a second language. Krashen (1981) suggests that there is not an adequate measure of the quality of empathy to allow for proper research of this factor's influence on the acquisition of an L2.

Guiora led the studies of empathy's relationship to L2 acquisition in terms of pronunciation in the early 1970's. He hypothesized that more empathetic individuals would be better listeners and better attuned to the native features of speech; therefore, empathetic individuals would acquire a more native-like proficiency in pronunciation. He set out to study this phenomenon in 1972 by using a Micromomentary Expressions Test or MME to measure the quality of empathy.

Schumann, in 1975, also studied empathy through hypnosis of individuals and concluded that empathy was more than a factor in pronunciation in an L2, and had a positive relationship to overall success in L2 acquisition. Guiora continued his studies of empathy and pronunciation including his now famous alcohol studies where subjects were given alcoholic beverages believed to lower inhibitions and lessen ego boundaries. Guiora was highly criticized for these studies and many of his results supporting alcohol's relationship to improved pronunciation in an L2 have been discounted. Empathy remains an enigma in terms of how to measure this quality and accurately define its relationship to second language acquisition.

\subsubsection{Extroversion/Introversion}

Extroversion and introversion are personality characteristics that can influence language learning in a positive or negative way depending on the measured aspect. It is believed that extroverts, who are sociable and open to other people, are more successful in learning languages than introverts, because they have more contact with L2. On the other hand, well-organized and serious introverts are seen as better learners as far as the systematic study is concerned. This assumption has been only partially confirmed by the research results obtained by Naiman, Frohlich, Stern, and Todesco. in 1978 and by Swain and Burnaby in 1976. But, to be friendly and approachable does help in the development of communicative skills and has been supported by a few studies. Pritchard (1952), for example, has discussed this aspect.

\section{Research on Personality Traits}

Many researchers believe that personality has an important influence on success in language learning. Ellis (1985) claims that the effects of personality on SLA are difficult to investigate because these factors are not easy to define and measure as most of the tests used lack validity. Most of personality traits are dynamic and may change depending of a situation. It is important for a teacher to recognize students' personality in order to supply them with suitable instructions and create the accurate atmosphere for learning. The following is a brief discussion of some of the research done in the area:

\subsection{PhD theses on the Role of Personality in SLA}

As is evident in the section given above, most of the significant work on the relationship between personality and SLA has been done in the form of short research projects leading to research papers in eminent journals. And one can deduct from that the fact that the full fledged research projects leading to $\mathrm{PhD}$ theses still have to find a significant voice in the review of literature on personality and SLA. This idea was strengthened while going through some $\mathrm{PhD}$ research work done in various universities across the world. The following review of the five related $\mathrm{PhD}$ 
theses are discussed below:

\subsubsection{Relationship between Personality Type and Grade Point Average of Technical College Students}

Brenda Wilz in her PhD thesis on Relationship between Personality Type and Grade Point Average of Technical College Students (2000) wanted to determine if a relationship existed between personality type and grade point average of technical college students in the Computer Information Systems (CIS)-Network Specialist Program at Fox Valley Technical College in Appleton, WI. The instrument chosen was the Keirsey Temperament Sorter II which is a personality inventory that determines the four dimensions a person's personality including Extroversion vs. Introversion, Intuition vs. Sensing, Thinking vs. Feeling, and Judgment vs. Perception.

The Temperament Sorter II contained seventy questions and each student chose one of two possible answers to each question. The personality inventory was administered to third and fourth semester students in the CIS-Network Specialist Program during one class period. Sixty students chose to become involved with this .

The personality inventories were completed and the question responses were compiled in a spreadsheet. The tests were scored to determine which of the four dimensions of each student's personality type was more dominant. Grade point information was collected from the college. The Point-Biserial measure of correlation was used to analyze the data to determine whether a relationship exists between personality type and grade point average.

Other helpful information that was obtained from this study included composite personality type of students in the CIS-Network Specialist Program. Since the relationship between personality type and learning style is well documented, Brenda Wilz believed that this information could help CIS Instructors at Fox Valley Technical College to identify the most appropriate teaching methods for those personality types.

3.1.2 Study of Theories of Personality and Learning Styles; Some Implications and Sample Activities to Support Curriculum Change in a Higher Education TESOL Program in Syria

The review of the thesis written by M. Fadi Al Shalabi in 2003, titled as the Study of Theories of Personality and Learning Styles; some Implications and Sample Activities to Support Curriculum Change in a Higher Education TESOL Program in Syria is discussed in the following section.

This dissertation studied theories of personality and learning styles and introduces sample communicative activities to support the change in the Syrian curriculum. Chapter one gives an idea of the present TESOL (teaching English to speakers of other languages) situation in Syria highlighting the increasing need for change which was a consequence of using direct method as the only teaching method. It clarifies why the English teachers in Syria, need to look for new methods of teaching that would result in better learning environment. As a step towards achieving the change, this dissertation looks closely at theories of personality and learning styles because they are relevant to teaching and learning process.

Chapter two looks at theories of personality and focuses specifically on those that have close relation to English language learning. Chapter three lists learning styles with their definitions and looks in more detail at styles that have clear relation to the learning process. In chapter four, examples of communicative activities are suggested. These activities aim to unlock learners' awareness of themselves and to give teachers, in Syria, an opportunity to collect data about prevalent personality traits and preferred learning styles among learners. An action research, that involves English teachers and learners in Syria, is suggested in chapter five to achieve the aim. Finally, a number of problems that might be faced are identified and some recommendations are given for overcoming them.

3.1.3 An Exploration of Language learning Strategies and Learner Variables of Sri Lankan Learners of English as a Second Language with Special Reference to Their Personality Type

An Exploration of Language learning Strategies and Learner Variables of Sri Lankan Learners of English as a Second language with Special Reference to their personality Type (2004) by Indika Jananda Borala Liyanage is the third thesis that is chosen for review. This study explores the relationship between language learning strategies and learner variables of Sri Lankan learners of English as a Second Language (ESL) with special reference to their personality types to examine the implications these associations have for the teaching of ESL in the Sri Lankan sociocultural context. In order to investigate the above, a large and representative sample of the ESL population was chosen. The sample taken for analysis comprised 886 subjects from six secondary schools which operate under the Ministry of Education in the Sri Lankan government. These subjects belonged to three distinct subcultures as demarcated by their first language (L1), Religion and Ethnicity in Sri Lanka. Data were collected using two questionnaires - a language learning strategy inventory and a personality assessment questionnaire, between April 2002 and June 2002 in Sri Lanka. Two statistical tests, namely, Multivariate Analysis of Variance (MANOVA) and Univariate Analysis of Variance (UANOVA), were used to measure the associations between the learner variables and language learning strategies:. The findings showed differences in strategy use or rather the ways the three 
groups learn the target language indicating that these strategy choices are closely correlated to their personality type, gender and religion/ethnicity. The findings also indicate that these variables affect the strategy choices both as collective and individual forces and when working as collective forces there is a complex interplay between these variables. While this study clearly demonstrates the association between learner variables and language learning strategies, it acknowledges the possible dangers in discussing these associations in cross-cultural comparisons. It also suggests the need for more ethnographic research to further elucidate the findings obtained in the current study. Based on these findings in the current study, this thesis strongly argues that ELT pedagogy cannot be independent of the Sri Lankan sociocultural context. It is therefore strongly suggested that ELT pedagogies should possess the following features:

i. Develop within the socio -cultural contexts of the learners;

ii. Be orientated to the culture of speakers of a Sri Lankan variety of English;

iii. Incorporate teaching material based on rhetoric indigenous to their culture.

The study also shows the complexities of ESL instruction in the Sri Lankan socio-cultural context where its history, different cultures, first languages, ethnicities and religions all make a significant contribution to the learning/teaching of the target language. The challenge for teaching ESL in Sri Lanka is even higher given that all languages come with their own cultural, historical and ethnic trappings.

\subsubsection{Personality and Second Language Learning in a Defense Program of Modern Standard Arabic Studies}

Personality and Second Language Learning in a Defense Program of Modern Standard Arabic Studies written by Cheryl Lynn Shirley in May, 2007 is taken up as the fourth thesis for review. This study aimed to investigate the problem of the relationship between personality, when operationalized at the facet level of measurement, and second language learning.

The participants in this study consisted of 145 military students who were studying Basic Modern Standard Arabic (BMSA) at the Defense Language Institute, Foreign Language Center (DLIFLC) in Monterey, California. Students completed the Revised NEO Personality Inventory (Costa \& McCrae, 1993), the Defense Language Proficiency Test III, and a researcher designed demographic questionnaire.

Three canonical correlation analyses (CCA) were used to examine the interrelationships among three criterion measures of second language learning and varying combinations of predictor measures of personality.

In the end a significant relationship between personality and second language learning did not emerge when personality was operationalized at the domain level of measurement. Yet, when personality was operationalized at the facet level of measurement, an improved understanding of the relationship between personality and second language learning emerged, and this finding was significant. A third CCA of the criterion variables and 10 theoretically selected predictor variables was also significant. The implications of these findings, suggestions for improvements in the design of this study, and recommendations for future research in this area of inquiry are discussed.

3.1.5 Shyness and EFL Learning in Taiwan: A Study of Shy and Non-shy College Students' Use of Strategies, Foreign Language Anxiety, Motivation, and Willingness to Communicate

Hsiang-Ning Rebecca Chu in her thesis titled Shyness and EFL Learning in Taiwan: A Study of Shy and Non-shy College Students' Use of Strategies, Foreign Language Anxiety, Motivation, and Willingness to Communicate (2008) examined the interrelationship among shyness, L2 learning strategy use, L2 learning motivation, foreign language anxiety, and willingness to communicate. Participants were 364 students enrolled in either Freshman English or Sophomore English courses in a private university in Taipei. They were asked to fill out self-report questionnaires about their global shyness, strategy use and motivation regarding their English studies, the degree of foreign language anxiety they experienced in their current English class, and their willingness to communicate in both Chinese and English contexts.

Results indicated that non-shy students reported using strategies more often across all strategy types than their shy counterparts, with compensation strategies being used the most often, and social strategies the least often. In addition, results from a series of hierarchical multiple regressions showed that intrinsic motivation to know appears to be the most important predictor among all motivation regulations for all students' use of most of the strategies. Results also indicated that shyness, foreign language anxiety, and willingness to communicate in both Chinese and English were correlated. Students who reported experiencing more foreign language anxiety in their English class showed less willingness to communicate in both Chinese and English. Moreover, shyness and foreign language anxiety had a moderate positive correlation. Implications for research and practice are discussed at the end. 


\section{Conclusion}

Thus, the above given theses deal with the different aspects of relationships between a second language learner's personality and his/ her proficiency in the second language. The review is an attempt at summarizing the widely available theses. In general, the research does not show a single clearly-defined relationship between personality traits and SLA. The major difficulty is that of identification and measurement of personality characteristics. Most research on personality traits has been carried out within a quantitative research paradigm (i.e., an approach that relies on measuring learners' scores on personality surveys and relating these to language test performance). More qualitative research is needed to adequately capture the depth and complexity of the relationship. The reviewer is hopeful of getting access to other related works in the due course of her research work.

\section{References}

Brodkey, D., \& Shore, H. (1976). Student personality and success in an English language program. Language Learning, 26, 153-159. http://dx.doi.org/10.1111/j.1467-1770.1976.tb00267.x

Brown, D. H. (2000). Principles of language learning \& teaching (4th ed.). New York: Longman.

Child, I. L. (1968). Personality in culture. In E. Borgatta, \& W. W. Lambert (Eds.), Handbook of personality theory and research (pp. 80-101). Chicago: Rand McNally.

Ellis, R. (1985). Understanding second language acquisition. Oxford: Oxford University Press.

Gardner, R. C., \& Lambert, W. E. (1972). Attitudes and motivation in second language learning. Rowley, Mass.: Newbury House Publishers.

Gass, S. (1988). Integrating research areas: A framework for second language studies. Applied Linguistics, 9, 198-217. http://dx.doi.org/10.1093/applin/9.2.198

Guiora, A. Z., Beit-Hallahani, B., Brannon, R. C. L., Dull, C. Y., \& Scovel, T. (1972). The effects of experimentally induced changes in ego states on pronunciation ability in a second language: an exploratory study. Comprehensive Psychiatry, 13, 421-428. http://dx.doi.org/10.1016/0010-440X(72)90083-1

Johnson, K. (2001). An introduction to foreign language learning and teaching. Harlow: Pearson Education.

Krashen, S. (1981). Second language acquisition and second language learning. Oxford: Pergamon Press.

MacIntyre, P. D., \& Gardner, R. C. (1991). Methods and results in the study of anxiety and language learning: A review of the literature. Language Learning, 41(1), 85-117. http://dx.doi.org/10.1111/j.1467-1770.1991.tb00677.x

Naiman, N., Frohlich, M., Stern, H. H., \& Todesco, A. (1978). The good language learner. Toronto: Modern Language Centre, Ontario Institute for Studies in Education.

Peterson, C. (1992). Personality. New York: Harcourt Brace Jovanovich.

Pritchard, D. F. L. (1952). An investigation into the relationship of personality traits and ability in modern language. British Journal of Educational Psychology, 22(2), 157-158. http://dx.doi.org/10.1111/j.2044-8279.1952.tb02817.x

Raymond, P. (1982). Attitude, motivation and personality in second language acquisition: From macro approach to micro approach. TESL Talk, 13(1), 44-54

Schumann, J. H. (1975). Affective factors and the problem of age in second language acquisition. Language Learning, 25(2), 209-235. http://dx.doi.org/10.1111/j.1467-1770.1975.tb00242.x

Scovel, T. (1978). The effect of affect on foreign language learning: A review of the anxiety research. Language Learning, 28, 129-142. http://dx.doi.org/10.1111/j.1467-1770.1978.tb00309.x

Skehan, P. (1989). Individual differences in second language learning. London: Edward Arnold.

Stern, H. H. (1983). Fundamental concepts of language teaching. Oxford: Oxford University Press.

Swain, M., \& Burnaby, B. (1976). Personality characteristics and second language learning in young children: A pilot study. Working Papers on Bilingualism, 11, 76-90. http://dx.doi.org/10.1177/0261927X960151001

Williams, M., \& Burden, R. L. (1997). Psychology for language teachers: A social constructivist approach. Cambridge: Cambridge University Press.

Wright, D. S., \& Taylor, A. (1970). Introducing psychology. Harmondsworth: Penguin Books. 